\title{
Anticorpos anti-Toxoplasma gondii em carcarás (Caracara plancus) procedentes da região aeroportuária do Recife, Pernambuco, Brasil
}

\author{
[Antibodies to Toxoplasma gondii in Crested Caracara (Caracara plancus) from Recife Airport, \\ Pernambuco, Brazil] \\ L.T.R. Silva ${ }^{1}$, J.S.A. Silva ${ }^{2}$, D.C.V. Lima ${ }^{1}$, V.P.M. Rolim ${ }^{1}$, M.F.V. Marvulo ${ }^{3,4}$, \\ J.C.R. Silva ${ }^{1}$, R.A. Mota ${ }^{1}$, A.A.F. Oliveira ${ }^{1 *}$ \\ ${ }^{1}$ Universidade Federal Rural de Pernambuco - Recife, PE \\ ${ }^{2}$ Centro de Apoio ao Desenvolvimento Tecnológico - Recife, PE \\ ${ }^{3}$ Faculdade Max Planck - Indaiatuba, SP \\ ${ }^{4}$ Universidade Paulista - Campinas, SP
}

\begin{abstract}
RESUMO
Objetivou-se com este estudo pesquisar a ocorrência de anticorpos anti-Toxoplasma gondii em carcarás (Caracara plancus) capturados no Aeroporto Internacional do Recife/Guararapes Gilberto Freyre, Pernambuco, Brasil. Foram analisadas 115 amostras de soros sanguíneos pelo teste de aglutinação modificada ( $\mathrm{IgG}, \mathrm{MAT} \geq 25$ ) utilizando taquizoítos inativados em formalina. Do total de amostras analisadas, $5,21 \%$ (6/115) foram positivas para presença de anticorpos anti-T. gondii, 16,67\% com título $1: 25(1 / 06)$ e $83,33 \%$ (5/06) com título 1:50. A ocorrência de anticorpos em carcarás procedentes de região aeroportuária fomenta a preocupação em relação a aspectos ainda pouco elucidados, relacionados principalmente à inserção de aves silvestres na cadeia epidemiológica da toxoplasmose conectada à ação antrópica, tornando próxima a interação entre animais silvestres, domésticos e o homem. Dessa forma, é notória a necessidade de estudos relacionados à dinâmica de transmissão entre os diferentes genótipos existentes nessa tríade e sua relação com o meio ambiente, a fim de determinar a influência dessa espécie animal na cadeia epidemiológica da toxoplasmose.
\end{abstract}

Palavras-chave: aves de rapina, diagnóstico, sorologia, toxoplasmose

\begin{abstract}
The objective of this study was to investigate the occurrence of antibodies against Toxoplasma gondii in carcarás (Caracara plancus) captured in the Recife/Guararapes Gilberto Freyre International Airport, in the State of Pernambuco, Brazil. 115 samples of blood sera were tested by the Modified Agglutination Test technique (IgG, MAT 2 25) using tachyzoites inactivated in formalin. Of the total of the analyzed samples, 5,21\% (6/115) were positive for the presence of antibodies against $\mathrm{T}$. gondii, 16,67\% with a titer of 1:25 (1/06) and 83,33\% (5/06) with a titration of 1:50. The occurrence of antibodies in caracaras coming from airport region generate concern about aspects still poorly understood, mainly related to the inclusion of wild birds in the epidemiological chain of toxoplasmosis connected to human action, making close interaction between wild animals, domestic and man. Thus, the need for studies related to the dynamics of transmission between the different existing genotypes in this triad is evident as is its relationship with the environment to determine the influence of this animal species in the epidemiological chain of toxoplasmosis.
\end{abstract}

Keywords: raptors, diagnostic, serology, toxoplasmosis

Recebido em 1 de novembro de 2016

Aceito em 9 de junho de 2017

*Autor para correspondência (corresponding author)

E-mail: andreaafo@hotmail.com 


\section{INTRODUÇÃO}

Os sítios aeroportuários são frequentados por diferentes espécies de aves, que, em alguns casos, podem contabilizar cerca de 70 espécies. Entretanto, algumas espécies despertam o interesse da segurança aeronáutica, em virtude do risco de colisões com aeronaves, tais como: urubu-de-cabeça-preta (Coragyps atratus), quero-quero (Vanellus chilensis), pombodoméstico (Columba livia), suindara (Tyto furcata), coruja-buraqueira (Athene cunicularia) e o carcará (Caracara plancus), sendo atribuído a este último a capacidade de beneficiar-se das ações antrópicas (Luigi, 2006; Vitaliano, 2007).

A proximidade entre as aves e o homem, cuja ocorrência está relacionada principalmente ao desequilíbrio ecológico gerado pelo rápido crescimento das grandes cidades, pode facilitar a disseminação de agentes biológicos para novos hospedeiros e ambientes, estabelecendo-se, assim, novas relações entre hospedeiros e parasitos, além de proporcionar o aumento no risco de exposição a zoonoses de origem viral, bacteriana, fúngica ou parasitária (Silva, 2006), destacando-se entre estas a toxoplasmose.

A toxoplasmose resulta da infecção pelo protozoário Toxoplasma gondii. Os hospedeiros, aves e mamíferos, podem infectar-se principalmente por ingestão de bradizoítos em cistos teciduais, adquiridos em carne crua, ou pela ingestão de oocistos presentes em água ou alimentos (Toxoplasmosis, 2005). A infecção por T. gondii em aves denota uma importância epidemiológica, pois estas são consideradas biomonitores ambientais e podem sinalizar a contaminação do meio ambiente por oocistos do agente, bem como a infecção de roedores e pequenos mamíferos, uma vez que aves de rapina, como os carcarás, infectam-se principalmente pela predação desses animais e pela ingestão de cistos teciduais presentes na musculatura (Dubey et al., 2010).

A ausência de sinais clínicos em aves predadoras, incluindo o carcará, é comumente relatada em estudos experimentais, sendo, portanto, consideradas resistentes (Lindsay et al., 1991; Dubey et al., 1992; Vitaliano, 2007).

A detecção de anticorpos anti-T. gondii, com base em testes sorológicos, consiste em determinar a exposição ao agente, sendo o status sorológico do animal fator norteador na tentativa de isolamento do parasito (Dubey et al., 2016). Entre os testes sorológicos disponíveis, destacase a técnica de aglutinação modificada (MAT), considerada de alta sensibilidade para detecção de anticorpos em animais silvestres (Vitaliano et al., 2014; Dubey et al., 2016).

Nesse sentido, objetivou-se com este estudo pesquisar a ocorrência de anticorpos antiToxoplasma gondii em carcarás (Caracara plancus) capturados no Aeroporto Internacional do Recife, Pernambuco.

\section{MATERIAL E MÉTODOS}

O presente estudo foi aprovado pela Comissão de Ética no Uso de Animais (CEUA) da instituição (Licença $n^{\circ}$ 078/2016). A captura das aves foi realizada mediante a autorização ambiental fornecida pelo Ibama $\mathrm{n}^{\mathrm{o}}$ 005-F-2011.

As amostras séricas obtidas foram procedentes de carcarás capturados no Aeroporto Internacional do Recife/Guararapes - Gilberto Freyre (Fig. 1), que se situa em área urbana e limítrofe entre os municípios de Recife e Jaboatão dos Guararapes, no estado de Pernambuco. Localiza-se aproximadamente a $10 \mathrm{~km}$ do centro da cidade de Recife, nas coordenadas $08^{\circ} 07^{\prime} 53^{\prime \prime} \mathrm{S}$ e $34^{\circ} 55^{\prime} 05^{\prime \prime} \mathrm{W}$.

Foram avaliadas 115 amostras séricas obtidas de carcarás (Caracara plancus) capturados com armadilhas do tipo Tomahawk, dispostas na área verde do sítio operacional do aeroporto. Os carcarás capturados foram encaminhados em caixas de transporte ao Centro de Manejo do Programa Fauna nos Aeroportos Brasileiros, localizado no Aeroporto Internacional do Recife/Guararapes, em Recife-PE, para realização de exame clínico e avaliação do estado geral.

As aves foram anilhadas e submetidas à coleta de aproximadamente $1 \mathrm{~mL}$ de sangue, por ave, pela punção da veia jugular. As amostras foram acondicionadas em tubos coletores e centrifugadas para obtenção do soro sanguíneo. Após a obtenção dos soros, estes foram armazenados em microtubos de polipropileno, identificados, estocados em freezer a $-20^{\circ} \mathrm{C}$ e posteriormente encaminhados para processamento no laboratório. 




Figura 1. Vista aérea do Aeroporto Internacional do Recife/Guararapes - Gilberto Freyre. Recife, Pernambuco.

Fonte: Google Earth.

Para a detecção de anticorpos IgG anti-T. gondii, foi empregado o teste de aglutinação modificada (MAT), utilizando-se taquizoítos inativados em formalina (antígeno), seguindo protocolo descrito por Dubey e Desmonts (1987) e Alvarado-Esquivel et al. 2011. Para execução do teste, as amostras séricas foram previamente diluídas em microplacas de 96 poços com solução salina tamponada $(\mathrm{pH} \mathrm{7,2)}$ filtrada em membrana de policarbonato (porosidade de $0,22 \mu \mathrm{m})$. Para a realização do teste, foram utilizados soros controles positivo e negativo, com titulação previamente conhecida. Cada amostra sérica, incluindo os controles, foi submetida às diluições de 1:25, 1:50 e 1:500 (Andrade et al., 2016), sendo 1:25 o ponto de corte considerado. Posteriormente, adicionaramse $120 \mu \mathrm{L}$ do antígeno previamente diluído, homogeneizou-se e transferiu-se a mistura a outra microplaca de 96 poços (fundo em "U”), devidamente selada e incubada overnight em estufa a $37^{\circ} \mathrm{C}$. Após o período de incubação, procedeu-se à leitura considerando-se resultado positivo a formação de um tapete completo, e negativo a formação de botão bem definido na parte inferior do poço (Desmonds e Remington, 1980).
Os dados obtidos foram analisados descritivamente por meio das frequências absolutas e relativas.

\section{RESULTADOS E DISCUSSÃO}

Das amostras de soros analisadas pelo MAT, $5,21 \%(6 / 115)$ apresentaram anticorpos anti- $T$. gondii (MAT $\geq 1: 25)$. Do total de amostras reagentes, em relação à titulação, 83,33\% (5/6) apresentaram título de 1:50, e 16,67\% (1/6) título de 1:25.

A ocorrência de anticorpos anti-T. gondii constatada nas aves capturadas no aeroporto do Recife, possivelmente, relaciona-se à predação de roedores ou de pequenos mamíferos na região aeroportuária ou adjacências. Sabe-se que os carcarás são aves generalistas e oportunistas, adaptadas a caminhar e caçar no solo e que se alimentam de presas vivas ou em decomposição, sendo grande parte da dieta desses animais composta por roedores (Lindsay et al., 1991; Vargas e Bó, 2007; Vitaliano et al., 2010). Estes mamíferos são hospedeiros intermediários e estão expostos a todas as formas infectantes do 
parasito (Meireles et al., 2004), sendo o elo na cadeia epidemiológica de transmissão do agente para as aves.

O aeroporto do Recife é visivelmente cercado pela malha urbana (Fig. 1) e residências informais; comumente essas áreas são deficientes em saneamento básico e dispõem de restos de alimentos e água, o que, segundo Luigi (2006), constitui um ambiente propício e atrativo para roedores, que, por sua vez, servem de alimento para as aves no entorno do sítio aeroportuário.

A participação dessas aves na cadeia epidemiológica de transmissão do $T$. gondii ainda permanece passível de esclarecimentos. Embora estudos reportem a positividade de aves aos testes sorológicos, poucos avanços ocorreram em relação aos aspectos epidemiológicos, no entanto é relevante o desenvolvimento de inquéritos sorológicos e estudos para detecção do parasito por métodos diretos em aves, uma vez que estas possuem o status de biomonitores ambientais.

Em relação ao MAT, técnica considerada sensível na detecção de anticorpos anti- $T$. gondii em aves (Tian et al., 2012) e utilizada neste estudo, percebe-se uma diversidade de resultados obtidos, com emprego da mesma técnica, em diferentes países. Na França, Aubert et al. (2008) pesquisaram anticorpos em 53 rapinantes de cinco espécies distintas, dos quais 19 foram positivos, correspondendo a $35,8 \%$. Nos EUA, Dubey et al. (2010) pesquisaram anticorpos antiT. Gondii em 29 espécies de aves, obtendo 9,9\% (38/382) de animais positivos. No México, Alvarado-Esquivel et al. (2011) identificaram $2,6 \%(17 / 653)$ de aves silvestres positivas, de diferentes espécies, incluindo rapinantes, com títulos variáveis de 1:25 a 1:800.

No Brasil, Soares et al. (2010) verificaram soropositividade de 4,3\% (3/69) para o T. gondii em emas (Rhea americana) procedentes do Centro de Multiplicação de Animais Silvestres em Mossoró, Rio Grande do Norte, utilizando o mesmo protocolo do presente estudo. Godoi et al. (2010), ao estudarem pombos infectados experimentalmente por $T$. gondii, relataram altos títulos de anticorpos nas primeiras semanas pósinfecção, no entanto ressaltam que pouco se sabe sobre o declínio de anticorpos nessas aves. No Arquipélago de Fernando de Noronha, Costa et al. (2012) identificaram títulos superiores a 1:5 em $79,7 \% \quad(157 / 197)$ das garças-vaqueiras (Bubulcus ibis). Recentemente, Andrade et al. (2016) analisaram 222 amostras de aves silvestres, de diferentes espécies, procedentes dos estados da Bahia e Paraíba, utilizando o MAT, sendo $1,3 \% \quad(3 / 227)$ das amostras soropositivas, relacionadas às espécies pipirapreta (Tachyphonus rufus (título 1:50)), juritigemedeira (Leptotila rufaxilla (título 1:50)) e caneleiro-enxofre (Casiornis fuscus (título $1: 25))$.

Em relação à espécie Caracara plancus, objeto deste estudo, percebe-se a escassez de artigos e a baixa amostragem empregada. Dentre os poucos estudos realizados na espécie, destaca-se o de Vitaliano et al. (2010), que infectaram experimentalmente carcarás (Caracara plancus) e demonstraram, pela técnica da reação de imunofluorescência indireta (RIFI), que houve soroconversão a partir do sétimo dia pósinfecção (dpi), entretanto houve uma redução gradativa de anticorpos circulantes até níveis indetectáveis constatados em uma ave ( $\left.68^{\circ} \mathrm{dpi}\right)$.

Em todos os estudos supracitados, exceção ao de Vitaliano et al. (2010), que empregou a RIFI, a pesquisa de anticorpos ocorreu de forma similar ao deste estudo. Assim, acredita-se que a técnica em si utilizada não tenha influenciado nos resultados quando se compara a esses estudos. Entretanto, outros fatores podem influenciar nas diferentes frequências de aves sororreagentes, tais como as diferentes condições climáticas predominantes nos locais dos estudos, o hábito alimentar inerente a cada espécie (Tian et al. 2012), a diversidade e a origem das espécies analisadas, bem como o tipo de manejo empregado, que diferem nos diversos estudos, além da diversidade de presas disponíveis, no caso de aves de rapinas, que são regionalmente diferentes. Ressalta-se também que diferentes resultados relacionados à soropositividade, bem como à titulação, em aves, podem ser atribuídos a distintos pontos de corte utilizados nos estudos, além do número de espécimes analisados.

Atrelado a isso, há de se considerar a diversidade de genótipos de $T$. gondii relacionados à fauna silvestre brasileira (Vitaliano et al., 2014), que, de certa forma, poderia determinar respostas imunológicas distintas. 
Durante o momento da captura, todos os carcarás apresentavam-se aparentemente saudáveis em seu estado geral, constatado posteriormente ao exame clínico. Tal fato foi observado por Lindsay et al. (1991), Dubey et al. (1992), Dubey (2002) e Dubey et al. (2010), que relataram a resistência de aves de rapina à toxoplasmose clínica, sendo geralmente de natureza subclínica.

Vitaliano et al. (2010) infectaram experimentalmente carcarás e não observaram o desenvolvimento da toxoplasmose clínica, embora os animais apresentassem títulos a partir do sétimo dia pós-infecção (dpi), com picos de produção de anticorpos detectados entre $15 \mathrm{e}$ 30dpi. Entretanto, ressalta-se que o aparecimento de sinais clínicos em estudos experimentais e a gravidade dos sinais estão diretamente relacionados à dose infectante e à virulência da amostra. Cabe ainda destacar o desconhecimento sobre os possíveis mecanismos que conferem resistência ao agente, para a espécie em questão.

\section{CONCLUSÕES}

A ocorrência de anticorpos em carcarás procedentes de região aeroportuária fomenta a preocupação em relação a aspectos ainda pouco elucidados, relacionados principalmente à inserção de aves silvestres na cadeia epidemiológica da toxoplasmose conectada à ação antrópica, tornando próxima a interação entre animais silvestres, domésticos e o homem. Dessa forma, é notória a necessidade de estudos relacionados à dinâmica de transmissão entre os diferentes genótipos existentes nessa tríade e sua relação com o meio ambiente, a fim de se determinar a influência dessa espécie animal na cadeia epidemiológica da toxoplasmose.

\section{AGRADECIMENTOS}

À Infraero e ao Centro de Desenvolvimento Tecnológico (CDT-UnB).

Ao Dr. Jitender P. Dubey (United States Department of Agriculture), pela concessão do antígeno.

\section{REFERÊNCIAS}

ALVARADO-ESQUIVEL, C.; RAJENDRAN, C.; FERREIRA, L.R. et al. Prevalence of Toxoplasma gondii infection in wild birds in Durango, Mexico. J. Parasitol., v.97, p.809-812, 2011.

ANDRADE, L.H.M.; LUGARINI, C.; OLIVEIRA, R.A.S. et al. Ocorrência de anticorpos anti-Toxoplasma gondii em aves silvestres de três unidades de conservação federais da Paraíba e da Bahia. Pesq. Vet. Bras., v.36, p.103-107, 2016.

AUBERT, D.; TERRIER, M.E.; DUMETRÈ, A. et al. Prevalence of Toxoplasma gondii in raptors from France. J. Wildl. Dis., v.44, p.172-173, 2008.

COSTA, D.G.C.; MARVULO, M.F.V.; SILVA, J.S.A. et al. Seroprevalence of Toxoplasma gondii in domestic and wild animals from the Fernando de Noronha, Brazil. J. Parasitol., v.98, p.679-680, 2012.

DESMONTS, G.; REMINGTON, J.S. Direct agglutination test for diagnosis of Toxoplasma infection: method for increasing sensitivity and specificity. J. Clin. Microbiol., v.11, p.562-568, 1980.

DUBEY, J.P.; DESMONTS, G. Serological responses of equids fed Toxoplasma gondii oocysts. Equine Vet. J., v.19, p.337-339, 1987.

DUBEY, J.P.; FELIX T.A.; KWOK, O.C.H. Serological and parasitological prevalence of Toxoplasma gondii in wild birds from Colorado. J. Parasitol., v.96, p.937-939, 2010.

DUBEY, J.P.; LAURIN, E.; KWOK, O.C.H. Validation of the modified agglutination test for detection of Toxoplasma gondii in free-range chickens by using cat and mouse bioassay. Parasitology, v.143, p.314-319, 2016.

DUBEY, J.P.; PORTER, S.L.; TSENG, F. et al. Induced toxoplasmosis in owls. J. Zoo. Wildl. Med., v.23, p.98-102, 1992.

DUBEY, J.P.A Review of toxoplasmosis in wild birds. Vet. Parasitol., v.106, p.121-153, 2002. 
GODOI, F.S.L.; NISHI, S.M.; PENA, H.F.J.; GENNARI, S.M. Toxoplasma gondii: diagnosis of experimental and natural infection in pigeons (Columba livia) by serological, biological and molecular techniques. Rev. Bras. Parasitol. Vet., v.19, p.237-243, 2010.

LINDSAY, D.S.; DUBEY, J.P.; BLAGBURN, B.L. Toxoplasma gondii infection in Red-Tailed hawks inoculated orally with tissue cysts. $J$. Parasitol., v.77, p.222-225, 1991.

LUIGI, G. Manual de controle do perigo aviário para aeroportos da rede INFRAERO. Rio de Janeiro: LIMA/COPPE/UFRJ, 2006.

MEIRELES, L.R.; GALISTEO, A.J.; POMPEU, E. et al. Toxoplasma gondii spreading in an urban area evaluated by seroprevalence in freeliving cats and dogs. Trop. Med. Int. Health, v.9, p.876-881, 2004.

SILVA, J.C.R. Toxoplasmose. In: CUBAS, Z.S.; SILVA J.C.R.; CATÃO-DIAS J.L. (Eds.). Tratado de animais selvagens: medicina veterinária. São Paulo: Roca, 2006. p.768-784.

SOARES, H.S.; ALVES, N.D.; PEREIRA, R.H.M.A. et al. Ocorrência de anticorpos antiToxoplasma gondii em emas (Rhea americana) do Centro de Multiplicação de Animais Silvestres de Mossoró, Rio Grande do Norte. Arq. Bras. Med. Vet. Zootec., v.62, p.489-491, 2010.
TIAN, Y.M.; DAI, F.Y.; HUANG, S.Y. et al. First report of Toxoplasma gondii seroprevalence in peafowls in Yunnan Province, Southwestern China. Parasites Vectors, v.5, p.205, 2012.

TOXOPLASMOSIS. Paris: OIE, 2005. Available in: <http://www.cfsph.iastate.edu/Factsheets/pdfs/to xoplasmosis.pdf.> Accessed in: 09 Mai. 2016.

VARGAS, R.J.; BÓ, M.S. Diet of the southern caracara (Caracara plancus) in Mar Chiquita Reserve, Southern Argentina. J. Raptor Res., v.41, p.113-121, 2007.

VITALIANO, S.N. Infecção experimental em carcarás (Caracara plancus, Miller, J.F., 1777) com Toxoplasma gondii (amostra ME49). 2007. 65f. Dissertação (Mestrado em Medicina Veterinária) - Faculdade de Medicina Veterinária e Zootecnia, Universidade Estadual Paulista, Jaboticabal, SP.

VITALIANO, S.N.; MINEO, T.W.; ANDRE, M.R. et al. Experimental infection of crested caracara (Caracara plancus) with Toxoplasma gondii simulating natural conditions. Vet. Parasitol., v.172, p.71-75, 2010.

VITALIANO, S.N.; SOARES, H.S.; MINERVINO, A.H.H. et al. Genetic characterization of Toxoplasma gondii from Brazilian wildlife revealed abundant new genotypes. Int. J. Parasitol. Parasites Wildl., v.3, p.276-283, 2014. 